\title{
A Comparative Study on the Effect of Game and Speech Training on Nurses' Learning and Reminder of Emergency Trailer Drugs in Selected Military Hospitals
}

Amiri. $\mathrm{F}^{1}$

Pishghoi. SAH 2*

Aliyari. $\mathrm{SH}^{3}$

Habibi. $\mathrm{H}^{4}$

1- MSC Student Emergency Nursing, Faculty of Nursing, Aja University of Medical Sciences, Tehran, Iran.

2- ( ${ }^{*}$ Corresponding Author) Ph.D. in Nursing, Assistant Professor, Medical-Surgical Department, Faculty of Nursing, Aja University of Medical Sciences, Tehran, Iran.

Email: apishgooie@ahoo.com

3- Ph.D. in Curriculum Studies, Assistant Professor, Maternal Newborn Health Department, Faculty of Nursing, Aja University of Medical Sciences, Tehran, Iran.

4- MSc in Nursing, Instructor, Pediatric Department, Faculty of Nursing, Aja University of Medical Sciences, Tehran, Iran.

\begin{abstract}
Introduction: Nurse's dominance on tracheal drugs and the specific application of each of them is a vital factor in the success of patients' recovery. The inadequate knowledge of the nurse undoubtedly leads to the risk of losing the opportunity to save patients.
\end{abstract}

Objective: Therefore, the purpose of this study was to compare the effect of educational instruction and lecture on the amount of nurses' learning and reminders of emergency trauma drugs in selected military hospitals.

Materials and Methods: This semi-experimental study was conducted in 1397 in two hospitals selected by the Armed Forces. The sampling method was available and the sample size consisted of 32 participants in the group and 32 lecture groups. First tested for both groups. The lecture course was designed in a theoretical way during a two-part 45-minute session with a one-week interval. Participants in the group were divided into groups of 4 . And training in the form of a game designed through two 45-minute sessions with a two-week interval. Immediately and one month after the intervention, a post-test was performed for both groups. Data analysis was done using Fisher, t-test and Paired t-test using SPSS 20 software.

Results: The results showed that play and lecture methods after intervention with a significant level of $\mathrm{P}(\mathrm{P}<0.05)$ were effective on the learning and reminding of nurses from emergency trauma drugs. Also, the statistical results one month after intervention indicated that both methods were effective on nurses' learning and reminder, and the nurses had the most impact on the method of play.

Discussion and Conclusion: Considering the positive impact of learning through the game, nurses should be familiar with modern educational methods both within their job responsibilities and by using more attractive and practical methods to improve the quality of learning and to recall their teachings. Take an effective step.

Keywords: Games, Lectures, Learning, Reminders, Trail Drugs. 


\title{
مقايسهى تأثير آموزش به روش بازى و سخنرانى بر ميزان يادكيرى و يادآورى داروهاى ترالى احيا در يرستار ان بيمار ستانهاى منتخب نظامى
}

\author{
فرهاد اميرى'، "نسيد امير حسين يشيخويى"، شهلا عليارى"، هنخامه حبيبى"
}

جكيده

مقدمه: تسلط يرستار بر داروهاى ترالى و كاربرد مشخص هر كدام از آنها فاكتور حياتى در موفقيت احياى بيمار ان مىباشد.

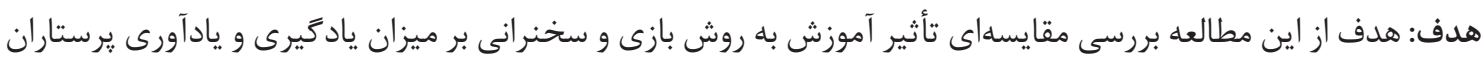

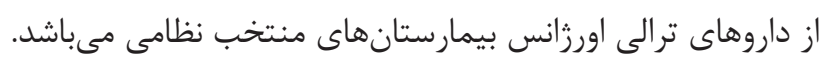

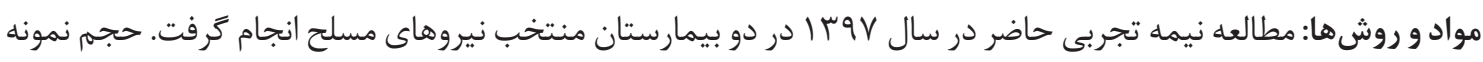

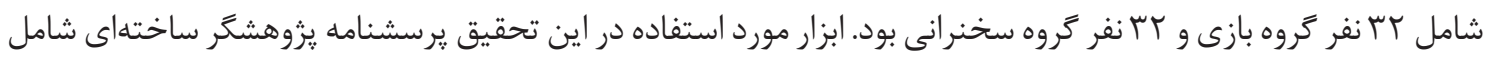

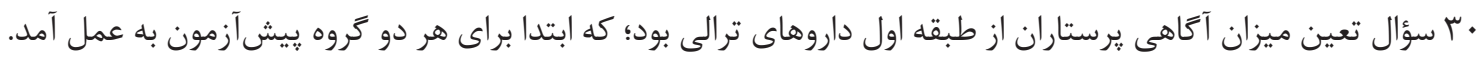

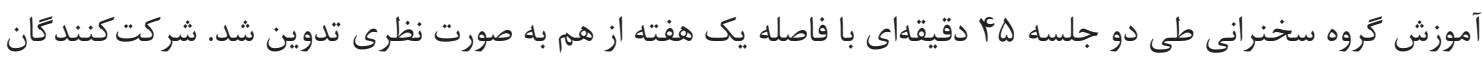

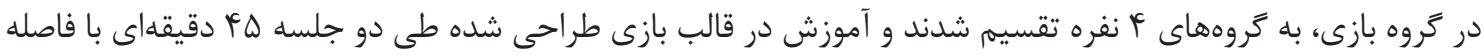

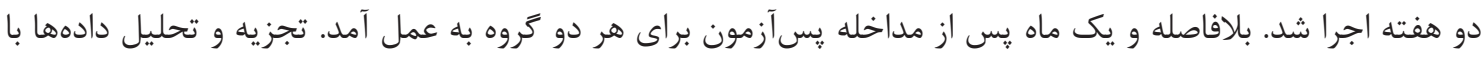

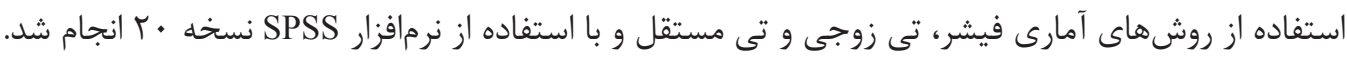

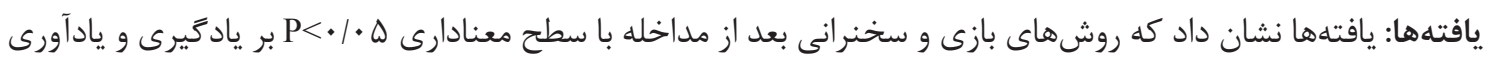

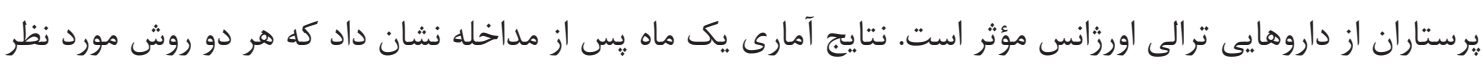

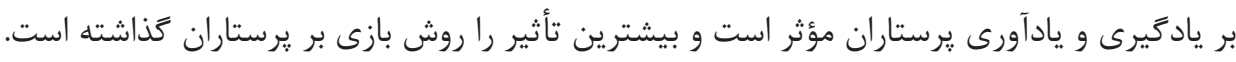

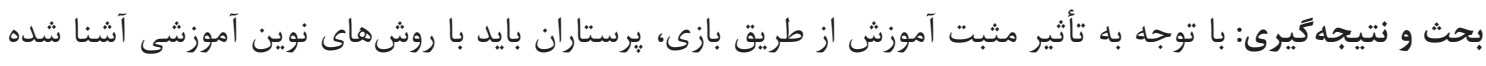

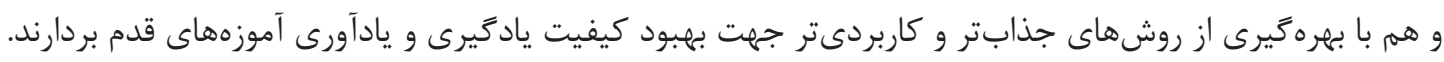

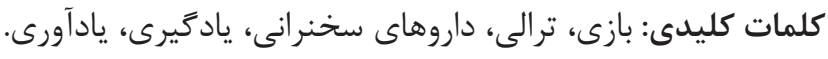

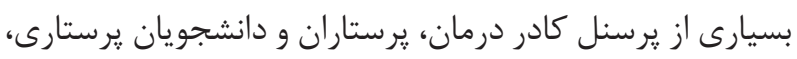
شناخت كافى در خصوص داروهاى ترالى و كلاً فرآيند احياء

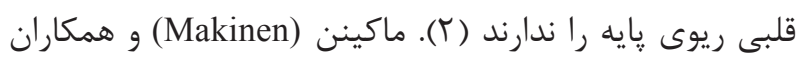

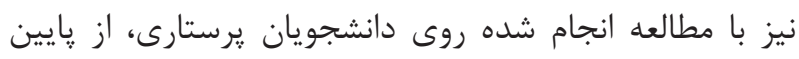
بودن و نامناسب بودن سطح علمى و عملكردى آنها زَارش
در محيطهاى بالينى، :رستاران اولين كسانى هستند كه در

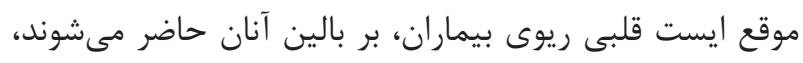

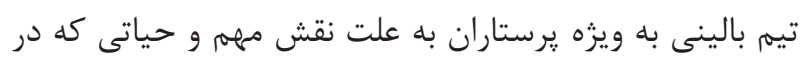

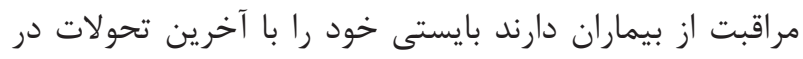

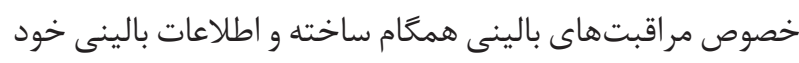


بودند. آنها به اين نتيجه رسيدند كه بازى يك روش آموزشى

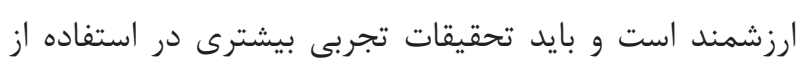
تكنيكهاى فعال (بازى) در آموزش ثرستارى انجام شود (^).

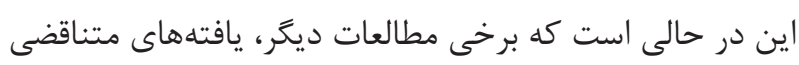

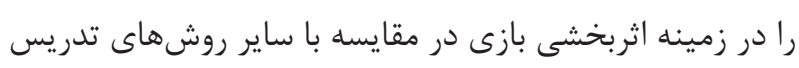

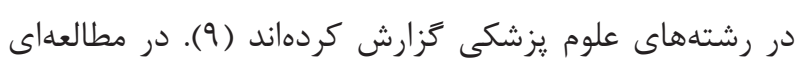

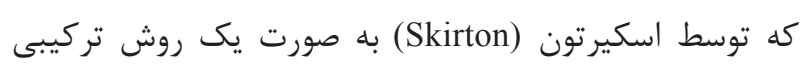

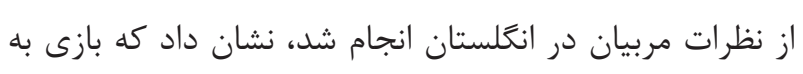
عنوان يك روش مؤثر براى تقويت آموختههايى است كه قبلاً

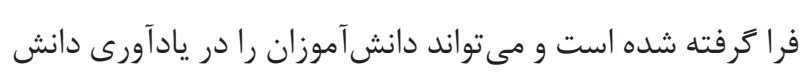

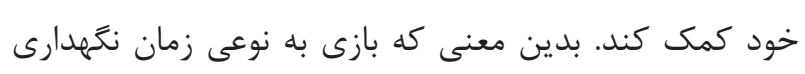

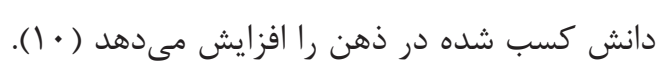

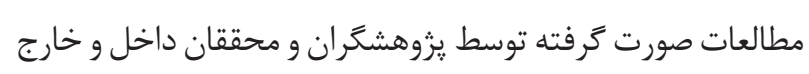

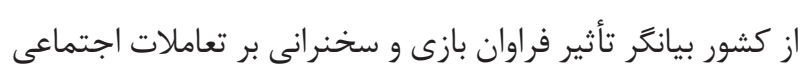

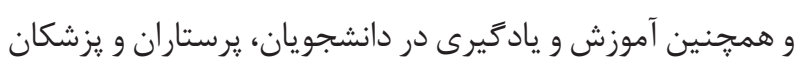

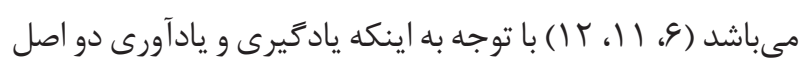

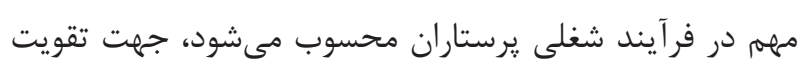

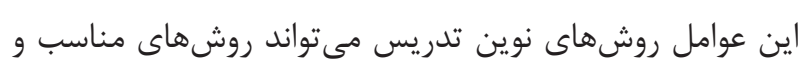

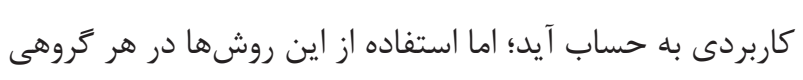

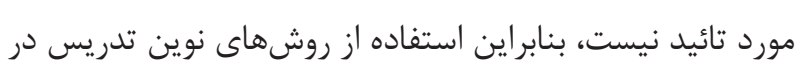

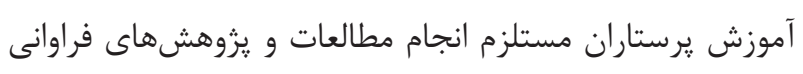

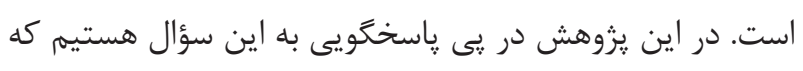

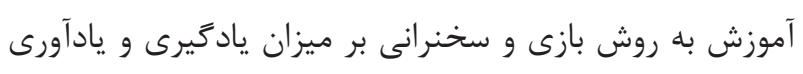

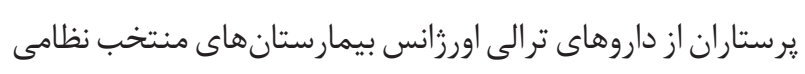

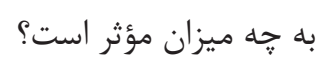

\section{موارد و روشها}

يزوهش حاضر مطالعهاى نيمه تجربى به صورت قبل و بعد است

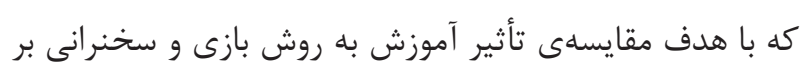

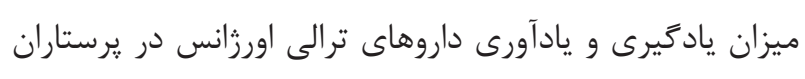
بيمارستان هاى منتخب نظامى كرمانشاه در سال و و 1 ا انجام شد. بيمارستان هاى مذكور به صورت تصادفى به دو كروه تقسيم شدند.

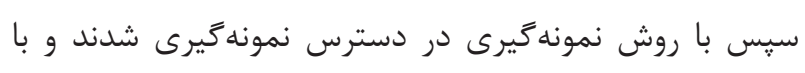

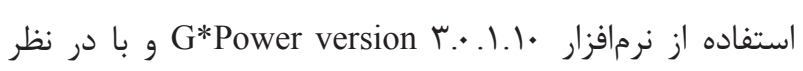

نمودهاند (r). مطالعات انجام شده در بيمارستانهاى كاشان نيز

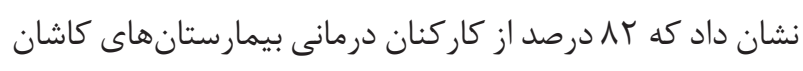
داراى آكاهى ضعيف و ال درصد داراى مهارت ضعيف در زمينه

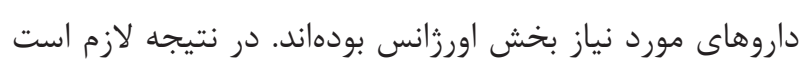

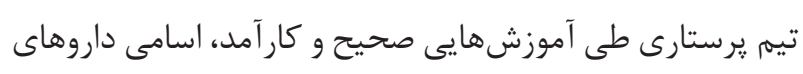

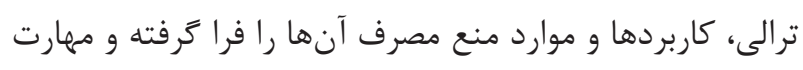

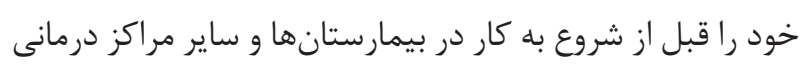

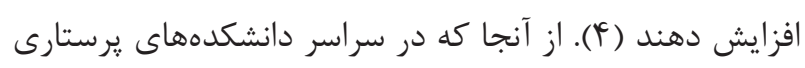

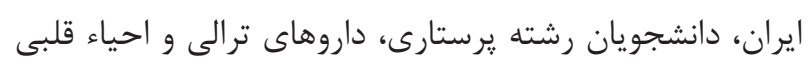
ريوى را در درس فوريتهاى يرستارى در سال دوم و يا سوم رئن

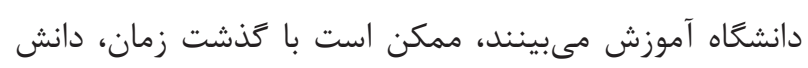

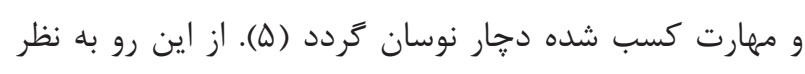

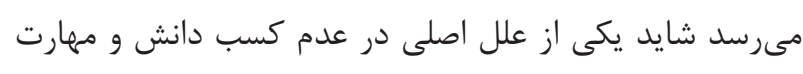

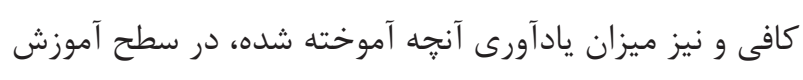
يرستارى از جمله آموزش داروهاى ترالى، شيوه تدريس و عدم ادمان

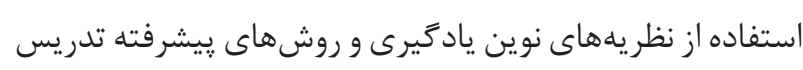

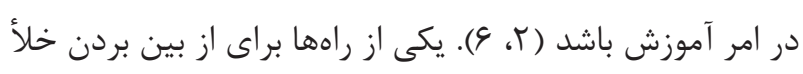

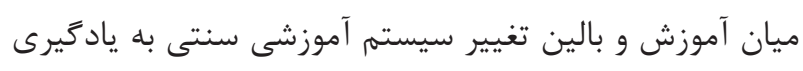
بر اساس مشاركت فعال يرستار است. مئتوان با استفاده از

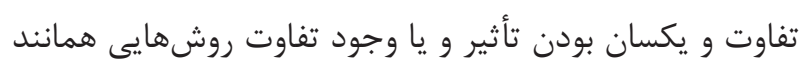

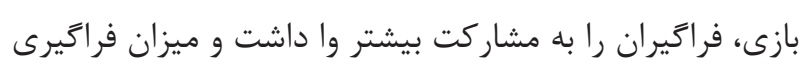

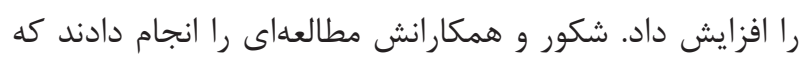

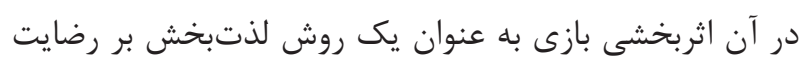

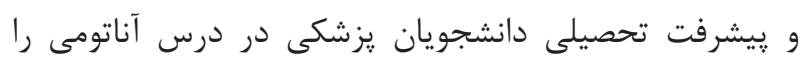

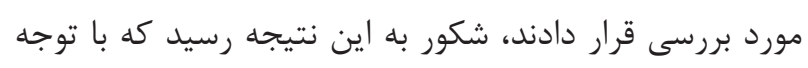

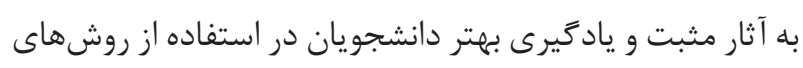

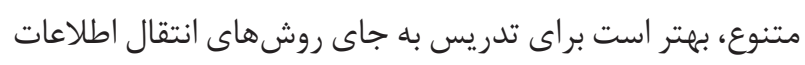

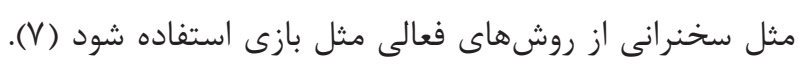

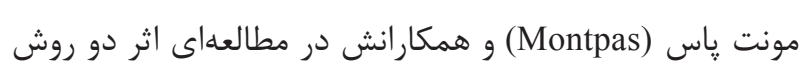

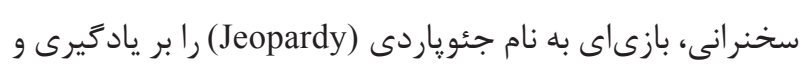

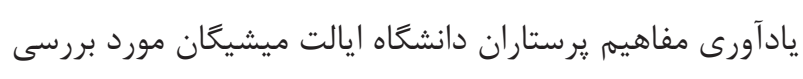

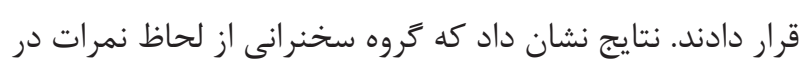

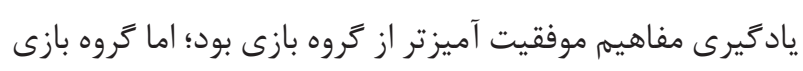
در حفظ و يادآورى مفاهيم در مقايسه با گروه سخنرانى بهتر 
تدريس نمود. 1 - سرى اول كارتها شامل نام يك داروى ترالى (سه سرى كارت داراى نام دارو) ץ- سرى دوم كارتها موارد مصرف مختص به هر داروى ترالى و د دارو دوز مصرفى

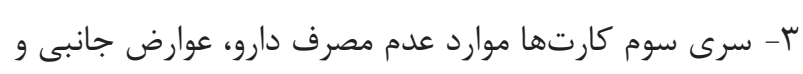

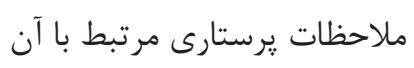

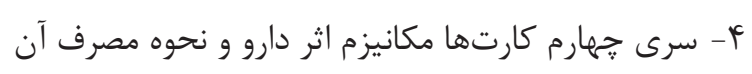

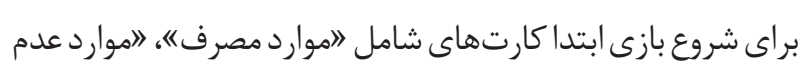

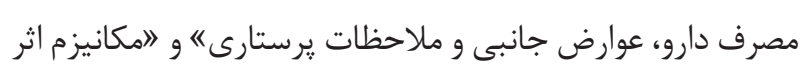

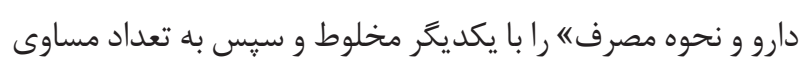

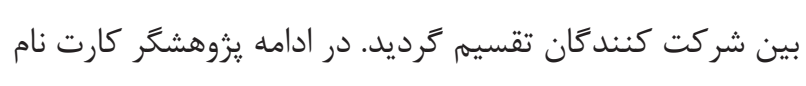

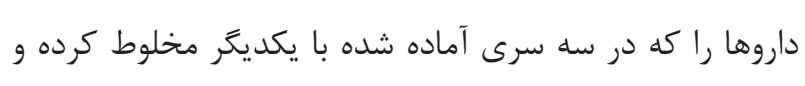

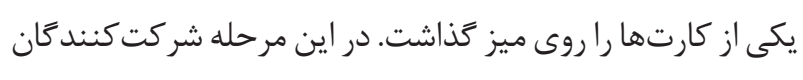
با توجه به كارتهايى كه در دست داشتند در صورتى كه موارد مرتبط با داروى مورد نظر بود آن را برمىداشتند. ״س از برداشتن كارت توسط شركت كننده، يزوهشكر كارت ديخرى را كه نام دارو روى آن است روى ميز مى كذاشت و مجدداً

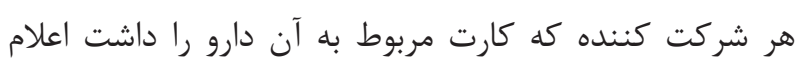

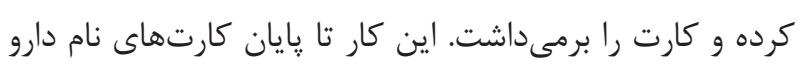

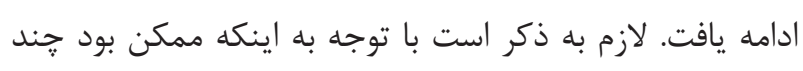

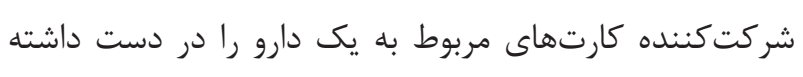

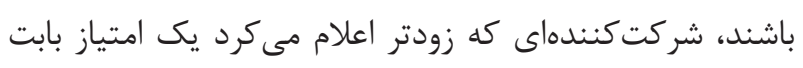

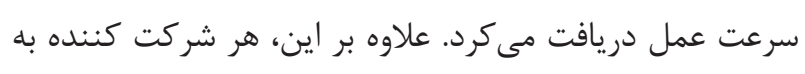

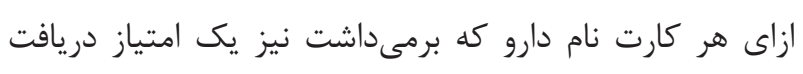

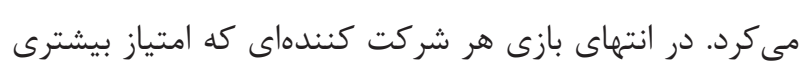

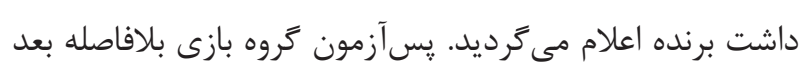
از اتمام بازى و يك ماه بعد انجام كَرديد.

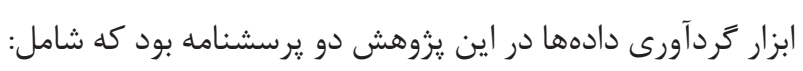

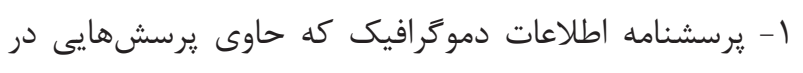
خصوص متغيرهاى سن، جنس، تحصيلات، سابقه كار، تأهل

بود. كَرفتن خطاى نوع اول ه • •، توان آزمون •و درصد و اندازه اثر

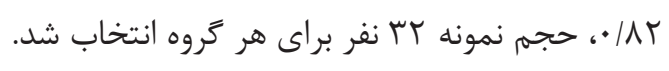

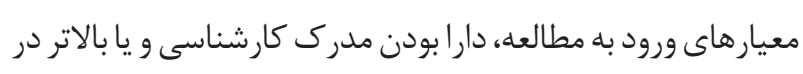

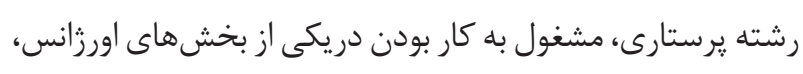

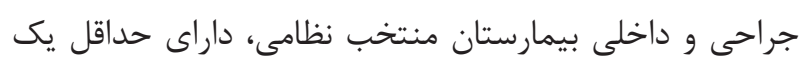

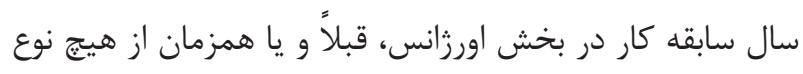
آموزش مدون و رسمى در زمينه تحقيق برخوردار نشده باشند

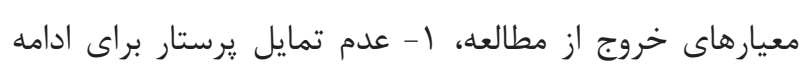

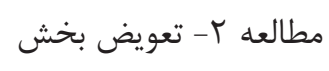
جهت انجام كار ابتدا مطالعه كتب و مقالات علمى موجود در در

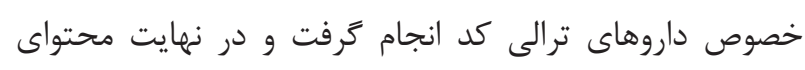
آموزشى با استفاده از تجربه اساتيد و صاحبنظران تران به به همراه بحث و تبادلنظر تهيه شد. محتواى يادگيرى خندين بار مورد

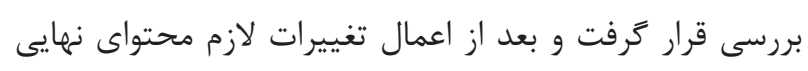

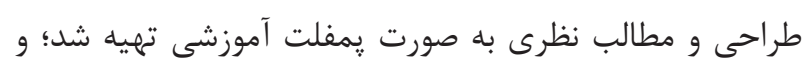

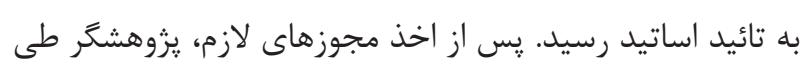

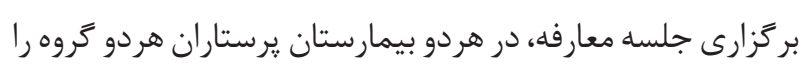

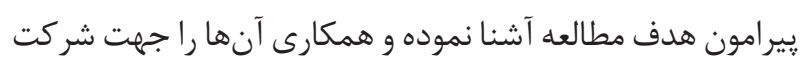

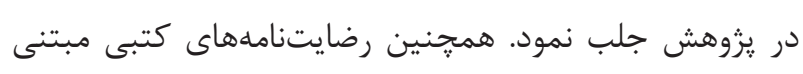

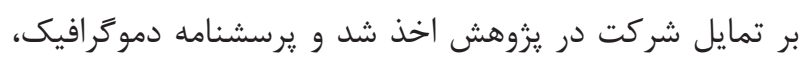
تكميل شد. يك هفته قبل از شروع جلسه آموزش ييش بـ آزمون

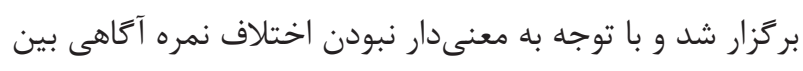
كروه سخنرانى و بازى مداخله انجام شد.

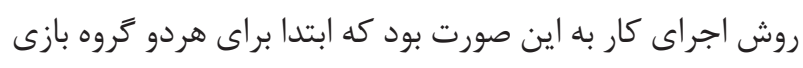

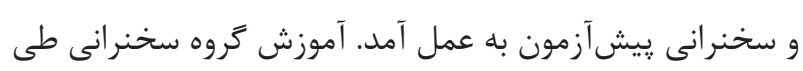

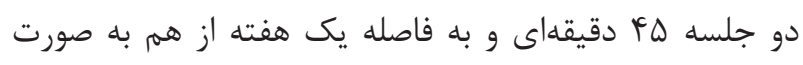

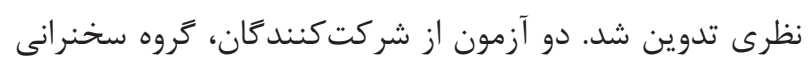

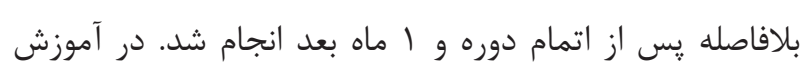

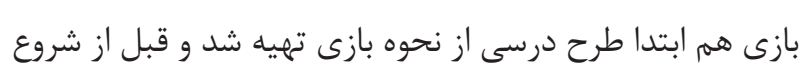
بازى به شركت كنند

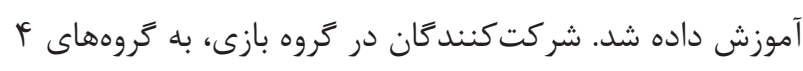

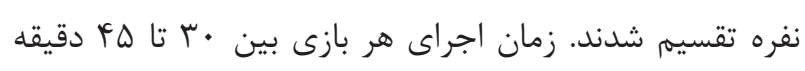

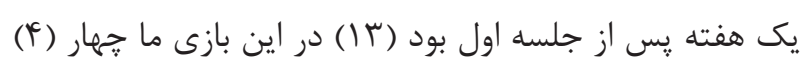

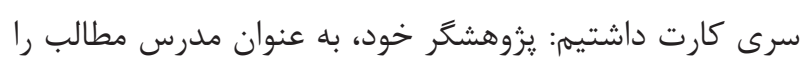


نوع متغيرها از آزمونهاى فيشر، تى زوجى و تى مستقل با

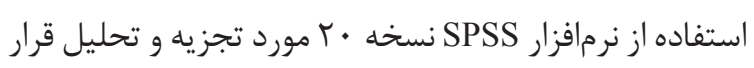
كرفت. روش كار در نمودار شماره ا ارائه شده است.

\section{يافتهها}

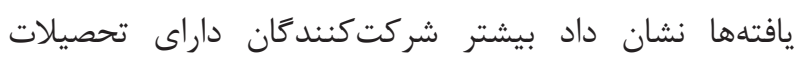

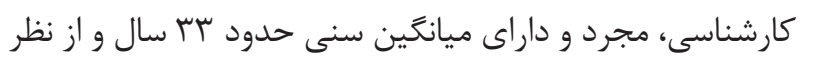

حاوى • r سؤال جهار زَزينهاى است كه براى هر سؤال صحيح

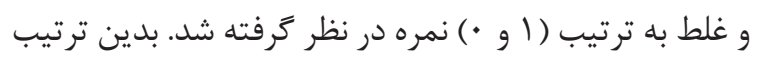

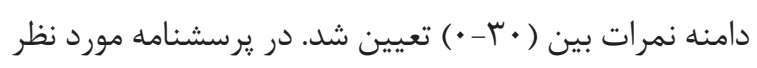

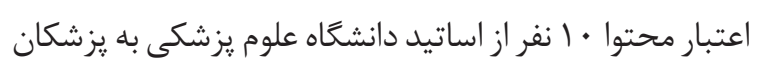
متخصص طب اورزانس انجام و مورد تائيد قرار كرفته است.

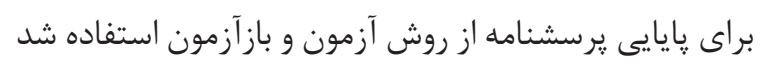

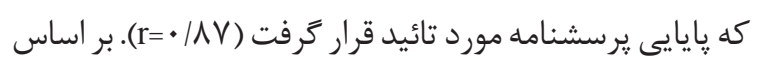

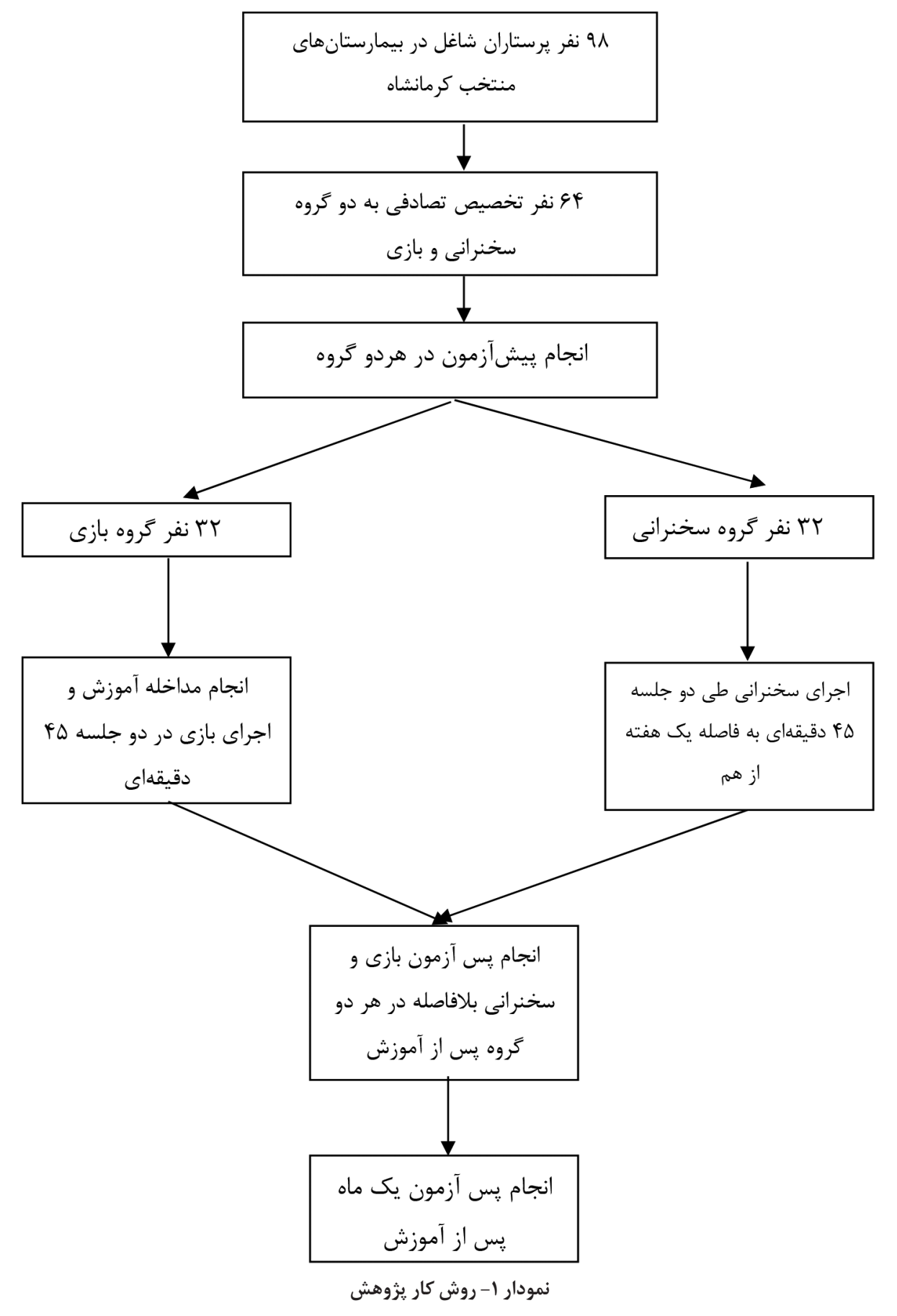


نمرات قبل و بعد در كروه بازى تفاوت معنادار وجود دارد و بازى

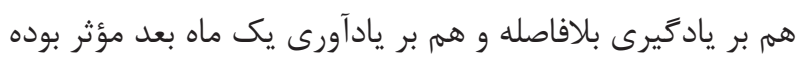

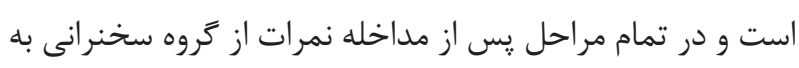

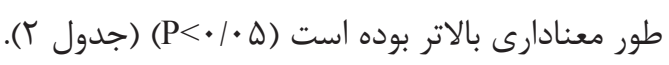

\section{بحث و نتيجه}

يافتههاى اين مطالعه نشان داد كه ميانگين نمرات يادكيرى

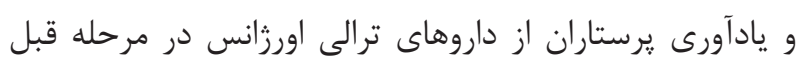

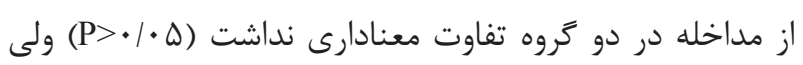

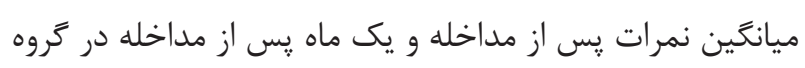

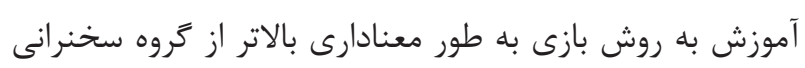

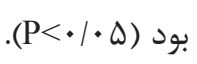

نتايج حاصل از مطالعه حاضر با مطالعه هاجز (Hodges) كه تأثير

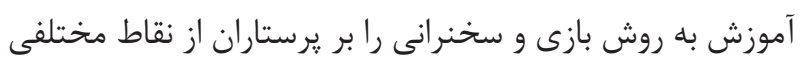

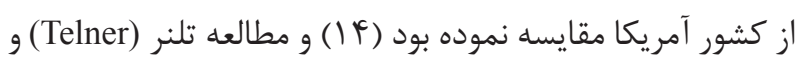

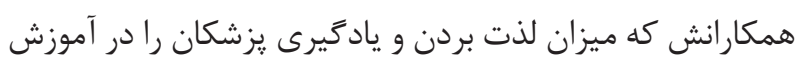

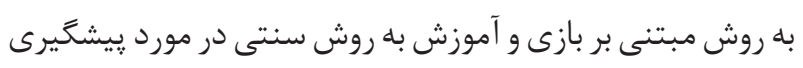

جنسيت در كروه سخنرانى مساوى اما در گروه بازى تعداد زنان

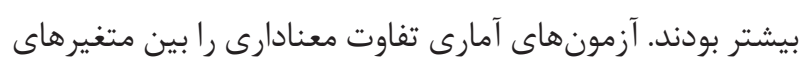

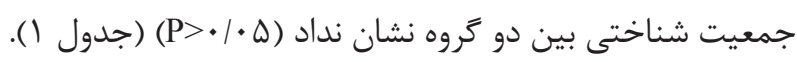

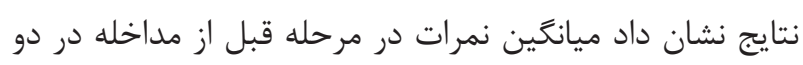

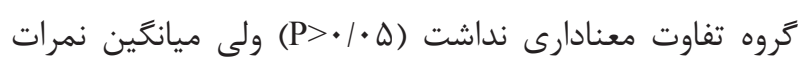

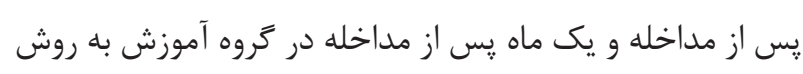

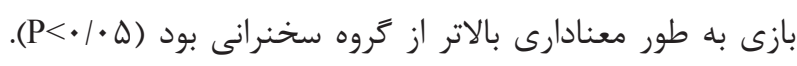

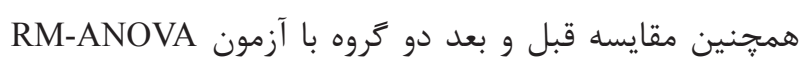

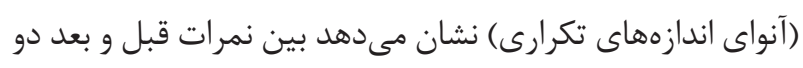
كروه تفاوت معنادار مىباشد و همانطور كه در نمودار شماره هم مىبينيد نمرات در كروه سخنرانى سير صعودى كمى داشته

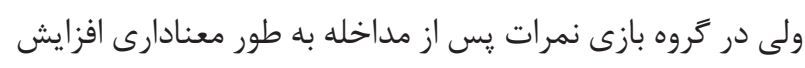

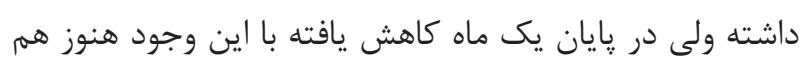

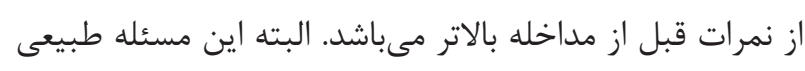

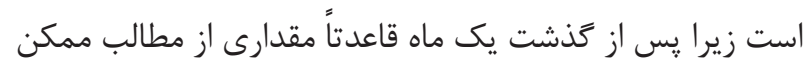

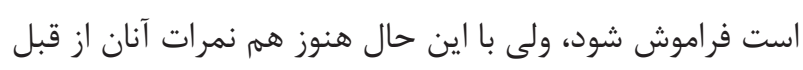

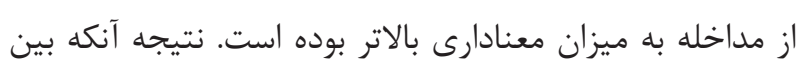

جدول ا- ويثَّى هاى دموكر افيك افر اد شركت كننده در كروه سخنر انى و بازى

\begin{tabular}{|c|c|c|c|c|c|}
\hline \multicolumn{2}{|r|}{ آزمونهاى آمارى } & 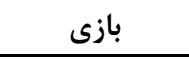 & سخنر انى & \multicolumn{2}{|c|}{ متغير } \\
\hline \multicolumn{2}{|r|}{ آزمون دقيق فيشر } & $19(/ . \Delta F / V)$ & $19(/ . \Delta \cdot)$ & مرد & \multirow{2}{*}{ جنسيت } \\
\hline \multicolumn{2}{|r|}{$\mathrm{P}=\cdot|9|$} & $\|(/ . F \Delta / \Gamma)$ & $19(/ .0 \cdot)$ & 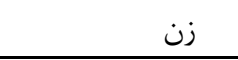 & \\
\hline \multirow{2}{*}{\multicolumn{2}{|c|}{$\begin{array}{c}\text { آزمون دقيق فيشر } \\
\text { P=•/א }\end{array}$}} & $r V(/ . \Lambda F / F)$ & $r \cdot(/ .9 r / \Lambda)$ & كارشناسى & \multirow{2}{*}{ تحصيلات } \\
\hline & & $\Delta(/ .1 \Delta / 9)$ & $r(/ .9 / T)$ & كارشناسى ارشد & \\
\hline \multirow{2}{*}{\multicolumn{2}{|c|}{$\begin{array}{c}\text { آزمون دقيق فيشر } \\
\text { P=.|4 }\end{array}$}} & $r)(/ .9 \Delta / 9)$ & IV $(/ . \omega r / 1)$ & مجرد & \multirow{2}{*}{ ت ت أهل } \\
\hline & & $11(/ . \mu Y / F)$ & $10(/ .49 / 9)$ & متأهل & \\
\hline $\mathrm{P}=\cdot 19$ & $\mathrm{t}=\cdot / \Delta \mathrm{T}$ & 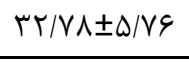 & $r r / \Delta \pm \Delta / 11$ & & سن (سال) \\
\hline $\mathrm{P}=\cdot / \Gamma \Delta$ & $\mathrm{df}=9 \mathrm{r} \quad \mathrm{t}=. / 9 \mathrm{r}$ & $|r / \cdot 9 \pm q| \Lambda \mid$ & $1 T / \Delta 9 \pm 9 / 4 T$ & & سابقه كار (سال) \\
\hline
\end{tabular}

جدول r- مقايسه يادكيرى و يادآورى در دو كروه سخنر انى و بازى قبل و بعد از مداخله و يكى ماه بعد از مداخله

\begin{tabular}{|c|c|c|c|c|c|c|c|}
\hline \multirow{2}{*}{ آزمون آناليز آنواى } & \multicolumn{2}{|c|}{ يك ماه يس از مداخله } & \multicolumn{2}{|c|}{ يس از مداخله } & \multicolumn{2}{|c|}{ قبل از مداخله } & \multirow{2}{*}{ و و يادرآ يادرى تريرى } \\
\hline & انحراف معيار & ميانگَين & انحراف معيار & ميانگين & انحراف معيار & ميانغين & \\
\hline$F=r \cdot / r r$ & $\Delta / F F$ & $14 / 94$ & $F / \cdot \Delta$ & $\mid r / \cdot r$ & $y / 1$ & $11 / 4 r$ & سخنرانى \\
\hline \multirow[t]{4}{*}{$\mathrm{P}<\cdot / \cdots 1$} & $r / v q$ & $I V / F G$ & $F / V V$ & $r \cdot \mid \Lambda V$ & 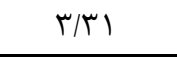 & $\mid r / T \Lambda$ & بازى \\
\hline & \multicolumn{2}{|c|}{$\mathrm{t}=r / \Lambda \& V$} & \multicolumn{2}{|c|}{$\mathrm{t}=\mathrm{V} / \cdot \mathrm{\Lambda}$} & \multicolumn{2}{|c|}{$t=\cdot / 9$} & \\
\hline & \multicolumn{2}{|c|}{$\mathrm{df}=q r$} & \multicolumn{2}{|c|}{$\mathrm{df}=q r$} & \multicolumn{2}{|c|}{$\mathrm{df}=q \mathrm{r}$} & t نتيجه آزمون t \\
\hline & \multicolumn{2}{|c|}{$\mathrm{P}=\cdot / \cdot \cdot \varphi$} & \multicolumn{2}{|c|}{$\mathrm{P}<\cdot / \cdot \cdot 1$} & \multicolumn{2}{|c|}{$\mathrm{P}=\cdot \boldsymbol{~}$} & مستقل \\
\hline
\end{tabular}


افزايش دهند (IV) (I ). عوامل مؤثر بر آشنا نبودن يرستاران با داروهاى

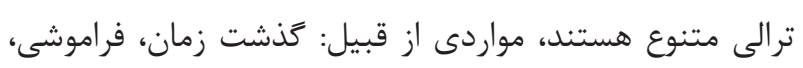

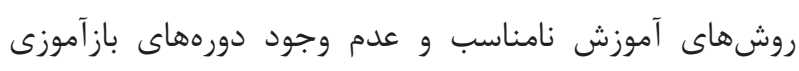

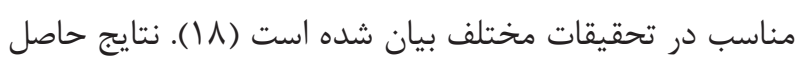

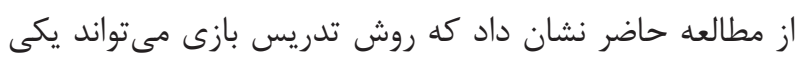

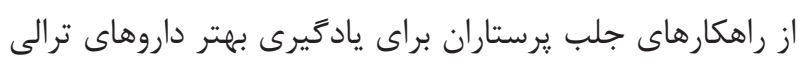

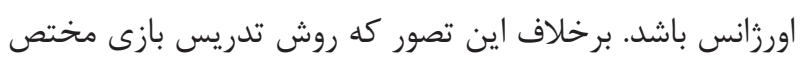

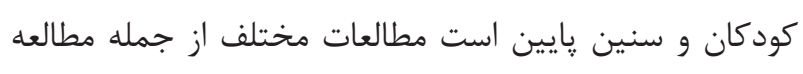
حاضر نشان داد كه در آموزش بزرَّالان از جمله ير برستاران نيز

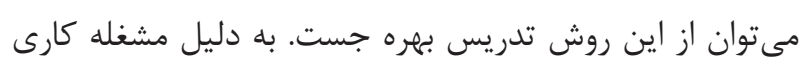

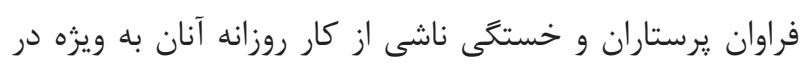
بخشهايى نظير بخشهاى ويزه و اورزانس به نظر مىرسد جهت آنس آموزش مطالبى كه فرار بوده و نياز به تمرين و تكرار دارند، روش بخدي

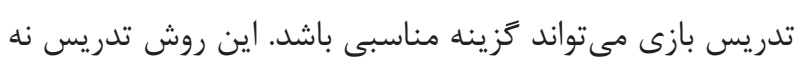
تنها موجب يادكيرى بيشتر مىشود بلكه موجب ماندكارى بيشتر

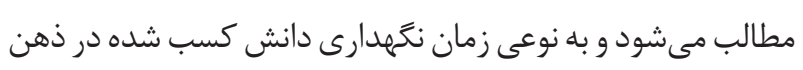

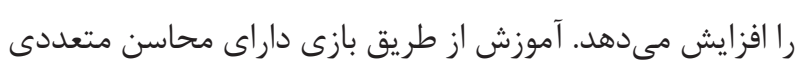

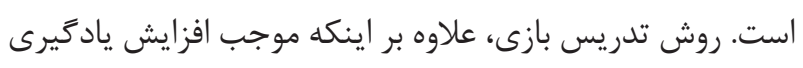
مىشود، داراى ياداش ذاتى است، جون شركت كنيند

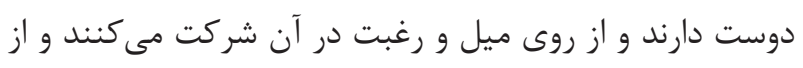

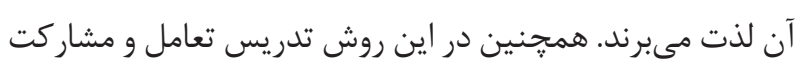

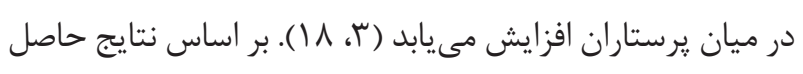

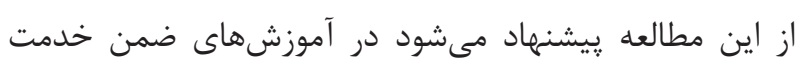

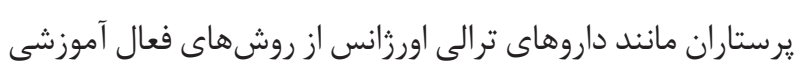
نظير بازى استفاده شود. از محدوديتهاى اين مطالعه مى توان اندان

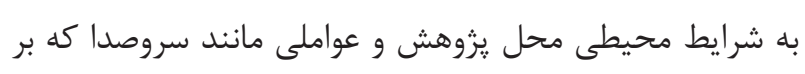
تمركز پرستاران تأثير كذار بود، اشاره نمود.

تشكر و قدردانى اين مقاله بر خرفته شده از يايان نامه دانشجوى كارشناسى ارشد

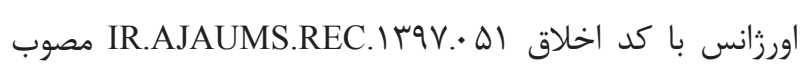

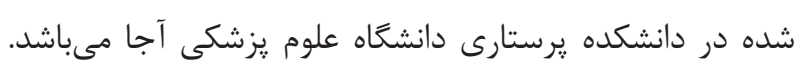

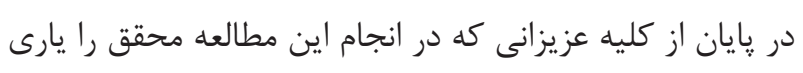
نمودهاند تقدير و تشكر به عمل مى آيد.

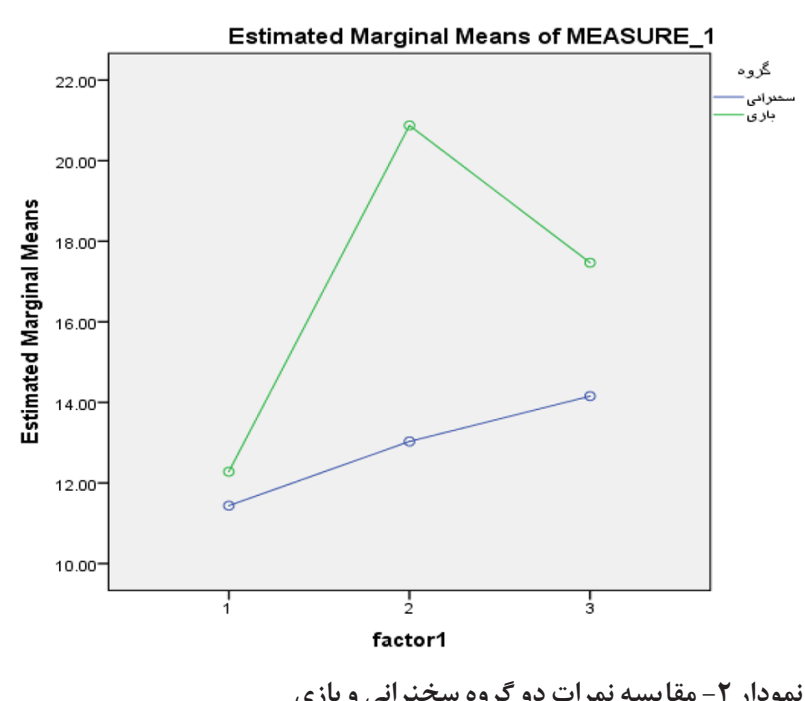

و مدير يت سكته مغزى مورد بررسى قرار داده بود (ه ( ) همخوانى

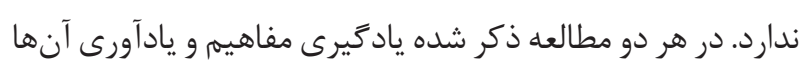
در هر دو تروه يكسان بود و تفاوت معنى دار نشان داده نشد. ولى نتيجه حاصل از اين يزوهش، با مطالعات شكور و همكاران، مونت پِاس و همكاران، فوجيموتو (Fujimoto) و همكاران مطابقت

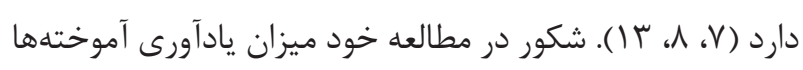

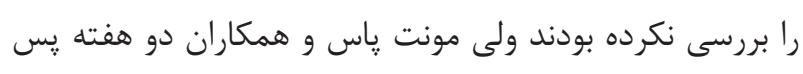

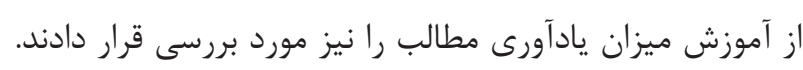

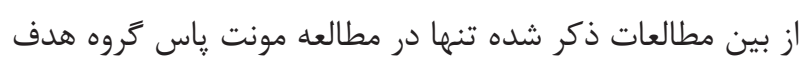
يرستاران بودند. در ساير مطالعات مطالعه بر روى دانش آموزان

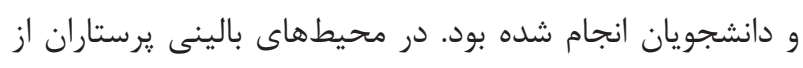

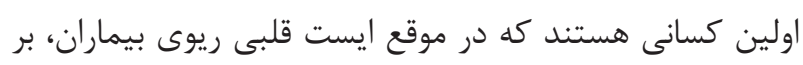

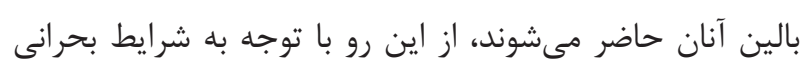

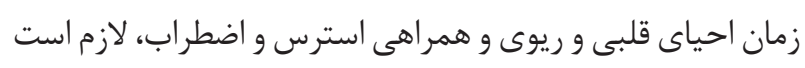

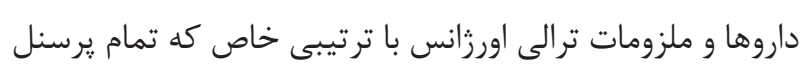

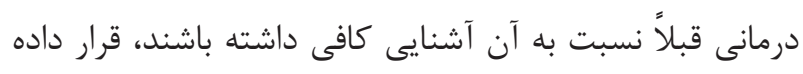

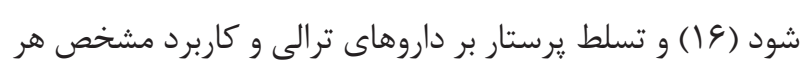

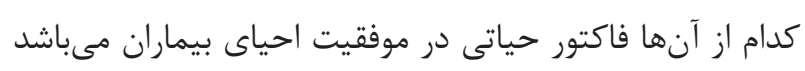

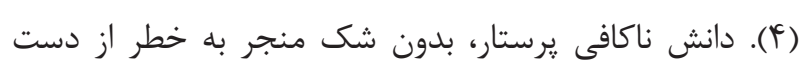

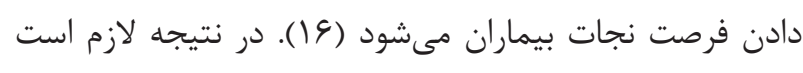

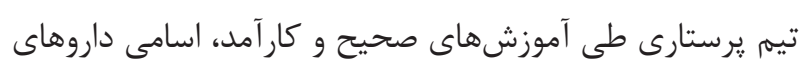

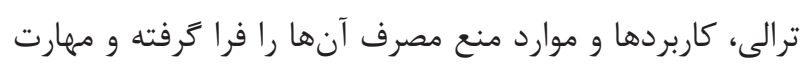
خود را قبل از شروع به كار در بيمارستانها و ساير مراكز درمانى موار مانى 
افزايش دهند (IV) (I ). عوامل مؤثر بر آشنا نبودن يرستاران با داروهاى

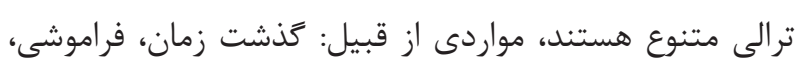

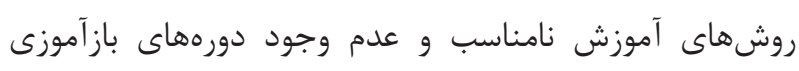

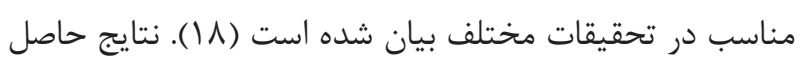

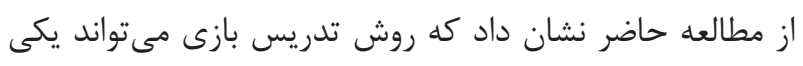

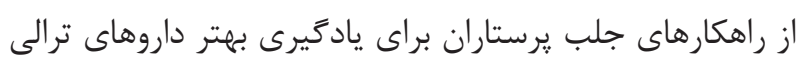

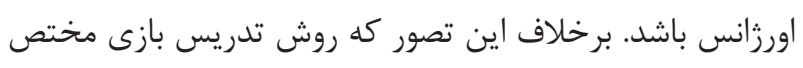

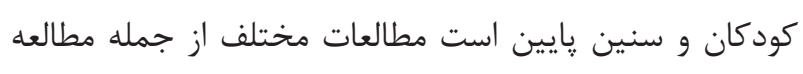
حاضر نشان داد كه در آموزش بزرَّالان از جمله ير برستاران نيز

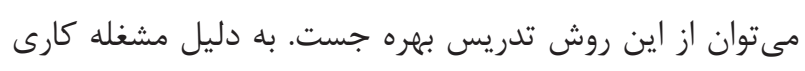

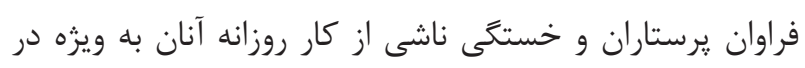
بخشهايى نظير بخشهاى ويزه و اورزانس به نظر مىرسد جهت آنس آموزش مطالبى كه فرار بوده و نياز به تمرين و تكرار دارند، روش بخدي

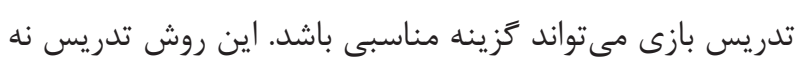
تنها موجب يادكيرى بيشتر مىشود بلكه موجب ماندكارى بيشتر

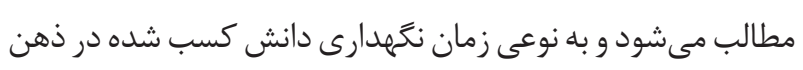

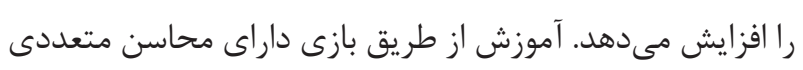

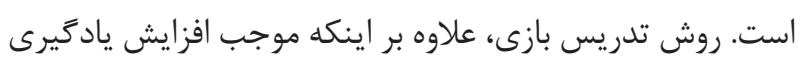
مىشود، داراى ياداش ذاتى است، جون شركت كنيند

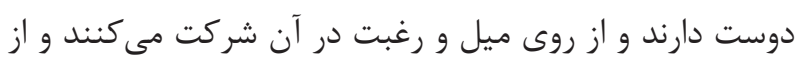

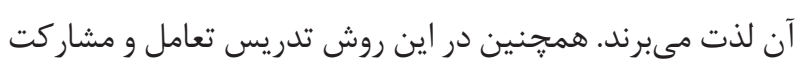

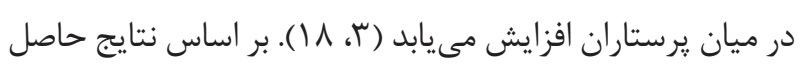

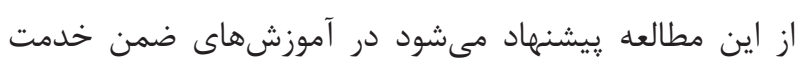

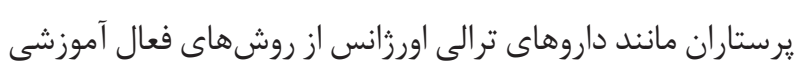
نظير بازى استفاده شود. از محدوديتهاى اين مطالعه مى توان اندان

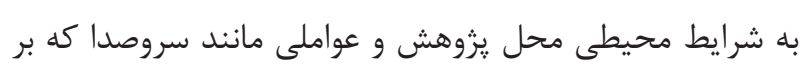
تمركز پرستاران تأثير كذار بود، اشاره نمود.

تشكر و قدردانى اين مقاله بر خرفته شده از يايان نامه دانشجوى كارشناسى ارشد

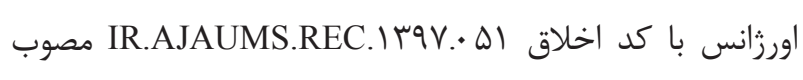

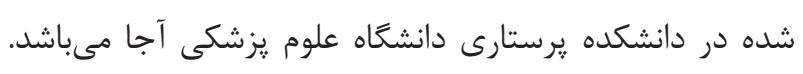

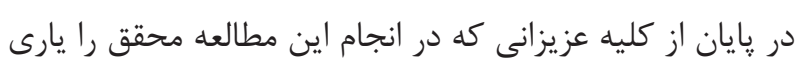
نمودهاند تقدير و تشكر به عمل مى آيد.

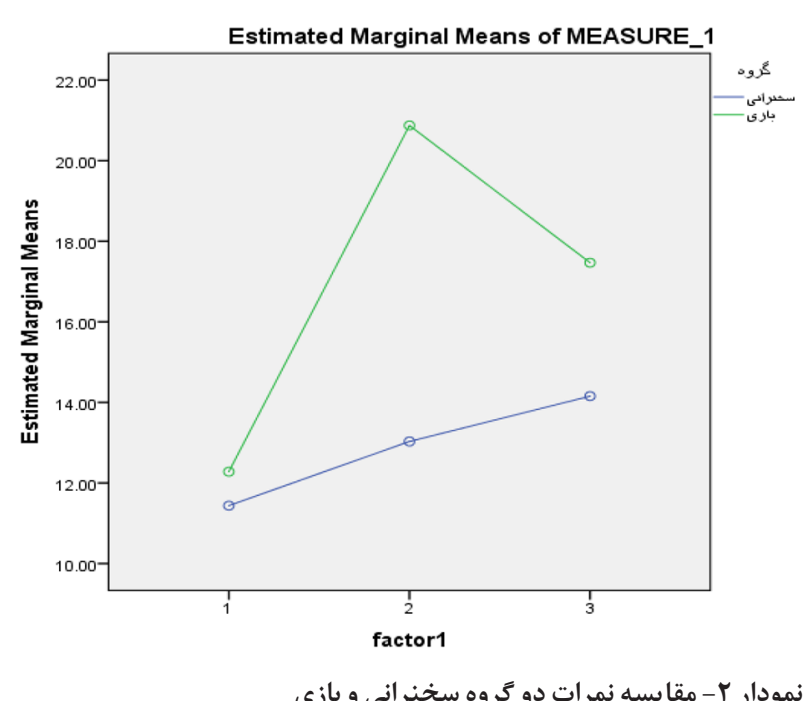

و مدير يت سكته مغزى مورد بررسى قرار داده بود (ه ( ) همخوانى

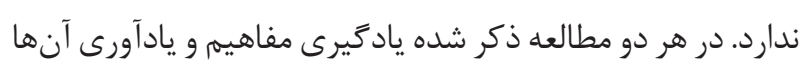
در هر دو تروه يكسان بود و تفاوت معنى دار نشان داده نشد. ولى نتيجه حاصل از اين يزوهش، با مطالعات شكور و همكاران، مونت پِاس و همكاران، فوجيموتو (Fujimoto) و همكاران مطابقت

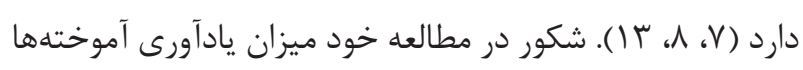

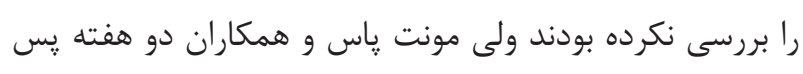

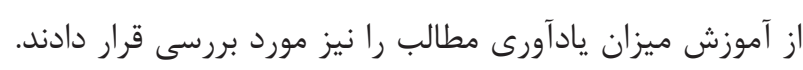

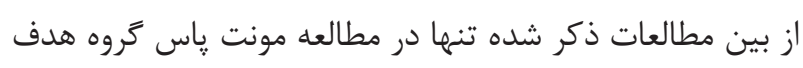
يرستاران بودند. در ساير مطالعات مطالعه بر روى دانش آموزان

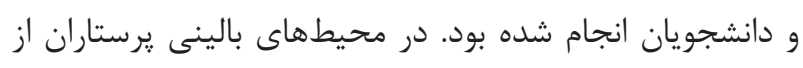

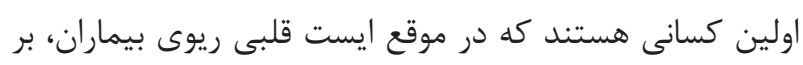

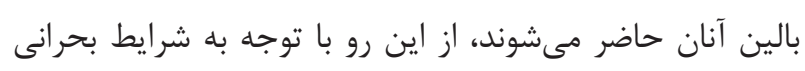

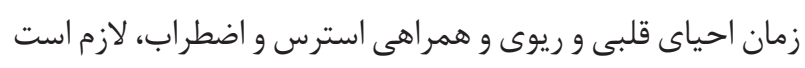

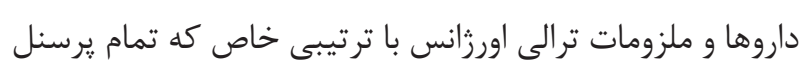

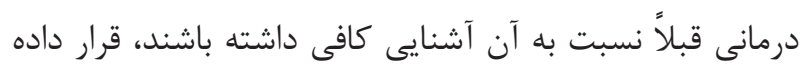

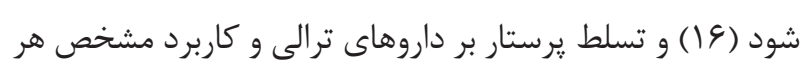

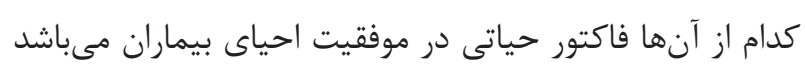

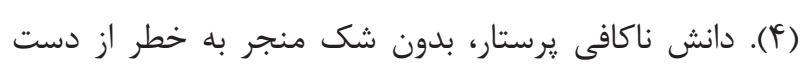

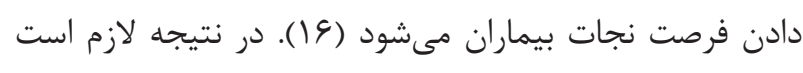

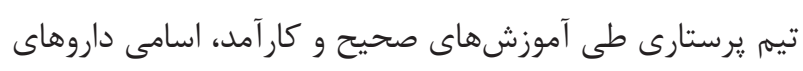

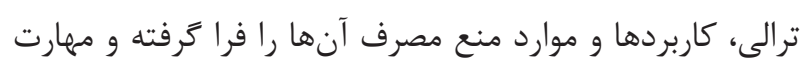
خود را قبل از شروع به كار در بيمارستانها و ساير مراكز درمانى موار مانى 


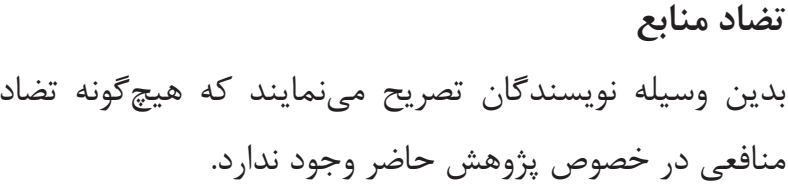

\section{References}

1- Gold N, Pulford BD, Colman AM. The outlandish, the realistic, and the real: Contextual manipulation and agent role effects in trolley problems. Frontiers in Psychology. 2014;5:35.

2- Kalhori RP, Jalali A, Naderipour A, Almasi A, Khavasi M, Rezaei $\mathrm{M}$, et al. Assessment of Iranian nurses and emergency medical personnel in terms of cardiopulmonary resuscitation knowledge based on the 2010 guideline. Iranian Journal of Nursing and Midwifery Research. 2017;22(3):184.

3- Mäkinen M, Axelsson Å, Castren M, Nurmi J, Lankinen I, NiemiMurola L. Assessment of CPR-D skills of nursing students in two institutions: Reality versus recommendations in the guidelines. European Journal of Emergency Medicine. 2010;17(4):237-9.

4- Ayazi Z, Malekpour Teharani A, Rahimi-Madiseh M. The effect of CPR training on performance of nurses in selected hospitals of Shahrekord University of Medical Sciences, 2010. Journal of Clinical Nursing and Midwifery. 2012;1.

5- Adib-Hajbaghery M, Azizi-Fini E. Longitudinal Study of CardioPulmonary Resuscitation Knowledge and Skills among Nurse Interns of Kashan University of Medical Sciences. Iranian Journal of Medical Education. 2013;13(2):134-45.

6- Gul RB, Boman JA. Concept mapping: A strategy for teaching and evaluation in nursing education. Nurse education in practice. 2006;6(4):199-206.

7- Shakour M, Haghani F, Shokri T, Bahramian H. The effect of game method on students' satisfaction and achievement in anatomy course. Journal of Isfahan Medical School. 2013;31(244).

8- Montpas MM. Comparison of "Jeopardy" game versus lecture onassociate degree nursing students' achievement and retention of geriatric nursing concepts: Wayne State University; 2004.

9- Madden C. Undergraduate nursing students' acquisition and retention of CPR knowledge and skills. Nurse Education Today. 2006;26(3):218-27.
10- Skirton H, Blakely G. Learning through play. Nursing standard (Royal College of Nursing (Great Britain): 1987). 2009;24(8):61.

11- Steinman RA, Blastos MT. A trading-card game teaching about host defence. Medical Education. 2002;36(12):1201-8.

12- Knowles C, Kinchington F, Erwin J, Peters B. A randomised controlled trial of the effectiveness of combining video role play with traditional methods of delivering undergraduate medical education. Sexually Transmitted Infections. 2001;77(5):376-80.

13- Fujimoto T, Fukuyama Y, Azami T, editors. Game-based learning for youth career education with the card game 'JobStar'. Conference: The 9th European Conference on Games Based Learning; 2015.

14- Hodges TL. Examination of gaming in nursing education and the effect on learning and retention $[\mathrm{PhD}$ thesis]. Auburn, Alabama: Auburn University; 2008.

15- Telner D, Bujas-Bobanovic M, Chan D, Chester B, Marlow B, Meuser J, et al. Game-based versus traditional case-based learning. Canadian Family Physician. 2010;56(9):e345.

16- Sodhi K, Singla MK, Shrivastava A. Impact of advanced cardiac life support training program on the outcome of cardiopulmonary resuscitation in a tertiary care hospital. Indian journal of critical care medicine: peer-reviewed, official publication of Indian Society of Critical Care Medicine. 2011;15(4):209-12.

17- Wilgis M, McConnell J. Concept mapping: an educational strategy to improve graduate nurses' critical thinking skills during a hospital orientation program. Journal of Continuing Education in Nursing. 2008;39(3):119-26.

18- Blakely G, Skirton H, Cooper S, Allum P, Nelmes P. Use of educational games in the health professions: A mixed-methods study of educators' perspectives in the UK. Nursing \& Health Sciences. 2010;12(1):27-32. 